\title{
OS MANUAIS ESCOLARES NA FRANÇA E A FORMAÇÃO DO CIDADẢO
}

\author{
Alain Choppin*
}

SÍNTESE - $O$ autor apresenta um rápido histórico do papel da instituição escolar na França na formação do cidadão: ele estabelece as finalidades, os objetivos e os conteúdos sucessivos de uma formação cívica que, há dois séculos, oscila entre a exposição de dados objetivos ("instrução") e a preocupação de suscitar a adesão a um sistema de valores ("educação") que ora se fundamenta em outros conteúdos disciplinares (história, moral, etc.) ora constitui uma disciplina autônoma, com seus programas, seus horários e seus manuais. Neste artigo, é enfatizada a produção, a difusão e o papel dos manuais de instrução ou educação ćvica, cujo recenseamento foi possivel pela primeira vez graças ao banco de dados Emmanuelle.

PALAVRAS-CHAVE - manuais escolares, formação do cidadão.
ABSTRACT - The author presents a brief history of the role that schools performed in the formation of the citizen in France: he establishes the ends, the objectives and the successive contents of a civic formation that, for two centuries, has been oscillating between the presentation of objective data ("instruction") and the preoccupation with developing a commitment to a value system ("education"), which at times is based on other disciplines (history, civics, etc.), at times constitutes an autonomous discipline with its own programs, classes, and manuals. In this article, it is emphasized the production, the diffusion and the role of the manuals for instruction or civic education, whose survey was possible for the first time thanks to the Emmanuelle data bank. KEY WORDS - students manuals, formation of the citizen.

\section{1 - Introdução}

É na segunda metade do século XVIII que surge, na França, a necessidade de oferecer uma instrução cívica à juventude. Desde 1752, o verbete "cidadão" da Enciclopédie, distinguindo com cuidado o status entre cidadão e sujeito, implica uma educação especifica. Os inúmeros tratados de educação publicados no final do Antigo Regime insistem quanto à necessidade de preparar os cidadãos para servir ao Estado e certos documentos reivindicatórios redigidos na primavera de 1789 apresentam exigências similares: o do Terceiro de Riom solicita assim "que se redija e se coloque entre os livros clássicos aqueles que contêm os princípios elementares da moral e da constituição fundamental do reino". ${ }^{1}$

* Pesquisador do Service de l'Histoire de l’Éducation - INRP/França. O texto foi traduzido por Julieta Beatriz Ramos Desaulniers e revisado por Patrícia Chittoni Ramos.

1 Archives parlementaires, França, v. 571.

\begin{tabular}{|l|l|l|l|l|l|}
\hline VERITAS & Porto Alegre & v. 43 & $\mathrm{n}^{2}$ especial & Dezembro 1998 & p. 183-192 \\
\hline
\end{tabular}




\section{2 - Da Revolução Francesa a Jules Ferry: tentativas abortadas}

De 1792 até o final do Diretório, todos os partidos concordam em reconhecer a necessidade de uma instrução moral e cívica, ${ }^{2}$ assim, as assembléias revolucionárias esforçam-se para traduzir esses princípios de ação em fatos confiando à instituição escolar, isto é, a partir de agora, a Escola da República, a missão de assegurar a formação dos futuros cidadãos. É o livro, garantia da ortodoxia dos conteúdos, que constitui então o suporte essencial dessa catequese cívica: "A Convenção encarrega seu comitê de Instrução pública de lhe apresentar os livros elementares dos conhecimentos absolutamente necessários para formar os cidadãos e declara que os primeiros serão os Direitos do Homem, a Constituição, o Quadro das Ações Heróicas e Virtuosas". ${ }^{3}$

A Declaração dos Direitos do Homem e do Cidadão constitui-se assim objeto de edições adaptadas à juventude, como a Déclaration des droits par demandes et par réponses pour en faciliter l'intelligence aux jeunes républicains dans les écoles primaires, surtout des campagnes [Declaração dos direitos por perguntas e respostas, para facilitar a inteligência dos jovens republicanos de escolas primárias, especialmente as do interior], de Réat ou então La Déclaration des droits de l'homme et du citoyen mise en vers [A declaração dos direitos do homem e do cidadão em versos], de Darnal. Iniciado no outono de 1793, Le tableau des actions héroïques et virtueuses [O quadro das ações heróicas e virtuosas], ao qual o decreto do 11 frimário ano II (1ำ de dezembro de 1793) confere um caráter oficial, é uma publicação periódica. Cinco números são publicados sob o título de Coletânea das ações heróicas e cívicas dos republicanos franceses entre dezembro de 1793 e julho de 1794, sendo distribuídos centenas de milhares de exemplares. ${ }^{4}$

Confiando a redação dos livros elementares a personalidades politicamente confiáveis ou organizando concursos cujos membros do júri tomam o cuidado de designar, os parlamentares manifestam sua preocupação constante em controlar de perto a composição dos livros elementares. De fato, trata-se de lutar contra as idéias do Antigo Regime e combater a religião com suas próprias armas, como atesta o título de diversas obras, tal como Catéchisme Républicain [Catecismo Republicano], de La Chabeaussièrre ou os Epîtres et Evangiles du Républicain [Epístolas e Evangelhos do Republicano], de Henriquez, dois dos manuais premiados no concurso organizado no ano $I . .^{5}$

Estamos bem longe dos objetivos assinalados por Condorcet para a formação dos cidadãos, no início da Revolução: "o Estado tem o dever de formar os cidadãos", sem, no entanto, "criar um tipo de religião política e roubar sua liberdade”. ${ }^{6}$

2. Ferdinand Buisson (dir.). Dictionnaire de pédagogie et d'instruction primaire. Paris, 1886, p. 399 (verbete "civilidade").

3 Decreto de 29 frimário, ano II (29 de dezembro de 1793), nomeado "décret Bouquier". Titulo II, art. $1^{2}$.

4 Ver JULIA, Dominique. Les trois couleurs du tableau noir. Paris: Belin, 1981, p. 208-211.

5 Entre 1792 e 1799, foram organizados 73 livros elementares de instrução cívica, conforme HansChristian, Les écrits pédagogiques sous la Révolution. Paris: INRP, 1989.

6 Rapport lu par Condorcet à l'Assemblée Legislative, de 20 e 21 de abril de 1792, seguido de um projeto de decreto. 
A finalidade não é mais informar, mas levar à adesão: "a vontade de dispensar uma educação triunfa sobre o desejo de dar uma instrução". " É assim colocada (e momentaneamente resolvida) a questão do papel da Escola na formação cívica do cidadão.

A história do ensino cívico na França oscilou entre dois objetivos dificilmente conciliáveis: por um lado, deve modelar indivíduos de acordo com as normas sociais ou dar-lhes uma informação que lhes permita exercer livremente seu espírito crítico na urbanidade? O manual, que constitui a elaboração concreta dos objetivos de aprendizagem, flutua necessariamente entre duas funções: veicular uma ideologia, um sistema de valores, ou então expor conhecimentos objetivos.

Porém, a formação dos cidadãos não constitui necessariamente uma disciplina escolar específica, distinta, autônoma: não se trata mais disso sob o I Império e sob a Restauração, que reintroduzem os deveres do sujeito e exaltam seu apego ao soberano e à sua familia: depois, durante meio século, da lei Guizot de 28 de junho de 1833, que organiza, sob a Monarquia de julho, o ensino primário, àquela de 28 de março de 1882, que funda a escola republicana, as raras noções que poderiam fazer parte da formação do cidadão encontram-se repartidas, disseminadas, diluídas entre a instrução moral e religiosa e a história, com objetivos freqüentemente distanciados dos ideais de 1789. Uma tentativa é bem conduzida por Hippolyte Carnot, sob a efêmera Segunda República, para reatar com o espírito da Revolução e restabelecer um ensino específico, mas ela rapidamente se desfaz ${ }^{8}$

\section{3 - De Jules Ferry à liberação: fundação de um ensino cívico}

O renascimento de um ensino civico integral produz-se em 1882, com a introdução oficial da "instrução moral e cívica" nos programas de ensino primário. A nova disciplina substitui a instrução moral e religiosa, até o momento ministrada pelas escolas públicas, e ocupa o primeiro grupo da lista de matérias ensinadas, o que demostra a importância que the é atribuída pelos defensores da laicidade. A votação do texto definitivo demandou quatorze meses de discussões e de debates acompanhados de freqüentes incidentes e reviravoltas de situação. ${ }^{9}$

O manual vai desempenhar um papel essencial na estratégia republicana: "Aquele que ó mestre do livro é mestre da educação", já declarava Jules Ferry em 5 de maio de 1879, diante dos membros da Comissão dos livros clássicos. De acordo com as conclusões de um relatório redigido pelo diretor do ensino primário, Ferdinand Buisson, o ministro assina, em 16 de junho de 1880, uma portaria que apela amplamente à iniciativa dos professores primários, no tocante à escolha de suas ferramentas de trabalho:

"Art. 1: Será estabelecida, a cada ano e em cada departamento, uma lista de livros reconhecidamente adequados para a utilização em escolas primárias públicas elementares e superiores.

7 MOUGNIOTTE, Alain. Les débuts de l'instruction civique en France. Lyon: P.U.L., p. 23.

8 Na primavera de 1848, o ministro fez distribuir aos professores primários o Manuel républicain de l'homme et du citoyen, de Charles Renouvier.

9 Consutar Mougniotte, op. cit., p. 35-65. 
Art. 2o: Nesse sentido, professores e professoras do ensino primário de cada distrito munidos de titulação, reunidos em conferências especiais, estabelecem, o mais tardar na primeira quinzena de julho, um lista de livros reconhecidamente apropriados para serem utilizados em escolas primárias públicas.

Art. 3o: Todas as listas assim estabelecidas são transmitidas ao inspetor da Academia. Uma comissão sediada no centro administrativo do departamento e composta de inspetores primários, do diretor e da diretora das escolas normais e dos professores adjuntos desses estabelecimentos, reunidos sob a presidência do inspetor da Academia, revisa as listas distritais e define o catálogo para o departamento".

Numa longa circular de 7 de outubro seguinte, Jules Ferry expõe aos reitores o espirito da nova regulamentação: "inspirem, guiem a inspeção e o ensino, previnam as variações e, finalmente, sem ter inscrito, nem desautorizado nenhum nome, façam pouco a pouco com que os interessados abandonem voluntariamente os [...] maus livros". Especifica, além disso, que a revisão das listas poderá ocorrer "caso omissões graves ou sistemáticas se produzirem". A administração central não impõe mais, porém continua a orientar, a aconselhar e, por vezes, a sancionar.

Ao confiar aos professores a livre escolha de suas ferramentas de trabalho mesmo tratando-se na realidade de um regime de liberdade vigiada - o ministério manifesta em relação a eles uma real e recente consideração, mas que lhes confere, por outro lado, novas responsabilidades, expondo-os individualmente às solicitações e às críticas. Uma "guerra de manuais" é assim provocada pela inclusão no Index, em 15 de dezembro de 1882, de inúmeros manuais de instrução cívica e moral em uso em escolas públicas, acusados de terem violado a neutralidade religiosa garantida pela lei de 28 de março de 1882 . Depois de ter considerado, face à agitação que segue, submeter as obras dessa natureza à formalidade de uma autorização especial, Jules Ferry põe fim à polêmica fazendo chegar a cada professor uma circular que ficou célebre: "O que importa não é a ação do livro, mas a sua [...] O livro é feito para você e não você para o livro [...] Insista sempre para que se compreenda que você empenha seu amor-próprio, ou melhor, sua honra, não para fazer com que se adote esse ou aquele livro, mas para atingir profundamente as jovens gerações através de ensinamentos práticos de boas regras e de bons sentimentos", 10

A nova liberdade concedida aos professores associa-se àquela usufruida pelos editores a partir de então para publicarem as suas obras: desde 1875, não são mais obrigados a solicitar e obter uma permissão preliminar da administração pública para cada uma das obras que destinam às classes dos estabelecimentos de instrução pública. Também o número de publicações clássicas aumenta de maneira espetacular nos anos de 1870 e passa, incluindo todas as disciplinas e todos os níveis, de 184 novos títulos em 1869 a 818, em 1881.

A introdução nos programas das escolas normais primárias (decreto de 22 de janeiro de 1881), depois das escolas primárias elementares (portaria de 27 de julho de 1882) de uma disciplina nova, a instrução cívica, opera-se portanto em um contexto ainda inédito, mas chamado a perdurar, que alia à liberdade de produção a liberdade de escolha e de utilização.

10 Circulaire du ministre aux instituteurs et institutrices publics, de 17 de novembro de 1883. 
Os programas de 1882, retomados sem mudança no decreto orgânico de 18 de janeiro de 1887, prescrevem: no curso elementar, "explicações bastante familiares a propósito da leitura, das palavras que podem evocar uma idéia nacional [...]"; no curso médio, "noções muito sumárias sobre a organização da França", essencialmente sobre 0 cidadão, suas obrigações e seus direitos, sobre o funcionamento da comuna, do departamento e do Estado; no curso superior, "noções mais aprofundadas sobre a organização política, administrativa e judiciária da França", "noções muito elementares de direito prático" e "entrevistas preparatórias à compreensão das noções mais elementares de economia política".

Os levantamentos bibliográficos efetuados no âmbito do programa de pesquisa Emmanuelle ${ }^{11}$ revelam que ao menos 267 novos manuais de instrução cívica destinados ao ensino primário elementar e/ou superior são publicados entre $1880 \mathrm{e}$ 1945, dos quais 200 antes da Primeira Guerra Mundial. ${ }^{12}$ A produção dos manuais de instrução cívica conhece, entre essas duas datas, uma evolução sensivel paralela àquela da produção editorial escolar no conjunto, ${ }^{13}$ mas ela é claramente mais contrastada: a forte carga simbólica da disciplina faz dela, parece, um mercado particularmente promissor e portanto mais suscetivel às menores modificações de programa. É assim que em três anos, 1882, 1883 e 1884, sessenta títulos são publicados para serem utilizados pelos três níveis do ensino elementar. Depois, a produção cai brutalmente, a menos de três novidades em média a cada ano: o mercado está então evidentemente saturado. A produção é relançada no início da década seguinte sob a influência de pelo menos dois fatores: a obrigação imposta aos alunos do curso superior de se munir de um manual de instrução moral e cívica (decreto de 29 de janeiro de 1890), a introdução, entre as exigências do certificado de estudos, de uma redação em que um dos três temas refere-se à instrução moral e cívica (portaria de 29 de dezembro de 1891). Em torno de vinte manuais são publicados entre 1892-93, mas o número anual de novos manuais permanece entre três e oito e isto até os primeiros anos deste século.

11 O programa de pesquisa Emmanuelle desenvolve-se desde 1980, a partir de inúmeros eixos maiores como: - história da política do livro escolar; - história econômica do livro e da edição escolar; história da estrutura interna do manual ou a capitalização das pesquisas efetuadas nessa área. 0 âmbito mais ambicioso, no entanto, refere-se ao recenseamento exaustivo da produção nacional (aproximadamente 120.000 títulos desde a Revolução Francesa, ou seja, em torno de 400.000 edições). Elaborado a partir de 1980, o banco de dados Emmanuelle, que conta hoje com mais de 25.000 referências, será proximamente acessivel pela Internet. Tal banco é considerado como um padrão bibliográfico nacional e internacional, já adotado em doze paises.Obras mais recentes sobre tal pesquisa: Les Manuels scolaires de 1789 à nos jours (Collection Emmanuelle, 8 volumes publicados); Les Manuels escolaires: histoire et actualité. Paris:Hachette Education, 1992, 240p.; "Le livre scolaire et universitaire" in Pascal Fouché (dir.), L'edition française depuis 1945. Paris: Editions du Cercle de la Librairie, 1998, p. 312-339.

12 Considerando o estado avançado dos trabalhos, algumas obras podem ainda escapar ao nosso controle, mas pode-se considerar que os números que apresentamos aqui possibilitam uma idéia fiel da produção total. Já foi possivel recensear 188 títulos de obras publicadas, utilizadas somente por escolas elementares entre 1872 e 1914, enquanto que Alain Mougniotte, que lhes consagrou sua tese, havia listado apenas 137.

13 Ver minha contribuição sobre o livro escolar, in Histoire de la édition française. Tome IV. Paris: Promodis, 1986, p. 280-305. 
Essa reativação da atividade editorial traduz também a mudança de atitude que manifestam os inúmeros professores quanto ao patriotismo em decorrência da crise boulangista (1885-1889). A análise e a comparação das listas de manuais estabelecidos em cada departamento de acordo com a regulamentação em vigor confirmam essa hipótese: em primeiro lugar, a opção aumentou consideravelmente: - o número de manuais citados passa de 91, em 1883, a 237 em 1909; depois, vários best-sellers usados em 1883, resistiram até 1909, como Eléments d'éducation civique et morale, de Gabriel Compayré ou Morale et enseignement civique, de Louis Liard, ambos utilizados em sete departamentos em dez ou ainda a Première année d'instruction civique, de Pierre Laloi, que inclusive melhorou seu escore de mais de 10\%, em um quarto de século. Em contrapartida, os manuais nacionalistas e revanchistas que eram amplamente difundidos nas salas de aula, no início dos anos 1880, não são citados a não ser esporadicamente. ${ }^{14}$ Essa desconfiança do corpo docente em relação ao patriotismo acentua-se na última década do século, marcada pelo caso Dreyfus, pela ascensão do sindicalismo, pela critica às instituições e pela emergência de idéias internacionalistas: "No ensino primário, a história, a instrução cívica e o estudo da língua francesa permitem a difusão de idéias pacifistas e antimilitaristas." ${ }^{15}$ Essa evolução é igualmente sensível na própria chamada dos títulos: a palavia pátria (ou uma de suas derivadas: patriota, patriotismo ou patriótico) encontra-se em treze títulos publicados pela primeira vez antes de 1894; encontra-se ainda duas vezes em 1895 e uma vez em 1897; depois, desaparece totalmente.

Os programas de 1882 apoiavam-se sobre três noções essenciais: o patriotismo, o civismo e a moral. Mas o refluxo das convicções patrióticas beneficia mais a educação moral do que a educação cívica: numerosos autores insistem sobre a dificuldade para os alunos mais jovens de compreender a estrutura e o funcionamento das instituições e, para os professores, de estabelecer as ligações com as outras disciplinas e de conceber práticas pedagógicas adequadas. ${ }^{16} \mathrm{~A}$ instrução moral - uma moral que ignora o espirito crítico e se limita a inculcar uma soma de regras necessárias a uma sociedade rural, comerciante, poupadora e democrática - sobrepuja a instrução cívica: já o decreto de 26 de julho de 1909 coloca a instrução cívica em segundo lugar (depois da moral) das matérias comuns a todas as sessões das escolas primárias superiores e dos cursos complementares; a portaria de 23 de fevereiro de 1923 confirma essa evolução passando a instrução cívica ao nivel de curso superior (alunos de 11-13 anos): compreende "noções sobre organização política, administrativa e judiciária da França" e sobre "o cidadão, seus direitos e deveres". Em 1938, a prorrogação da escolaridade obrigatónia de treze para quatorze anos levanta a questão dos conteúdos de ensino a serem dispensados durante esse ano complementar. Os programas de 23 de março de 1938 pre-

14 Esse estudo constitui um dos eixos em curso do programa de pesquisa Emmanuelle. Pretende-se analisar e comparar as listas de manuais utilizados pelas escolas primárias de cerca de trinta departamentos (ou seja, um terço do territónio nacional francês) entre 1883 e 1909, incluindo todas as disciplinas de ensino. A sua publicação ocorrerá em breve.

15

16 AUDIGIER, François. Éducation civique et morale: éléments d'histoire pour une réflexion sur les problèmes d'aujourd'hui. Documento de trabalho, fevereiro de 1988 (não publicado). 
vêem duas horas semanais de moral e de iniciação à vida cívica dos últimos períodos de estudos, mas com uma forte implicação do ensino na prática e no local: "A cultura geral é a mesma para todas as crianças da França. A cultura prática assume uma cor diferente conforme o meio, rural ou urbano, industrial ou agrícola e mesmo conforme as regiões". É a história - e, notadamente, a história contemporânea - que surge como o suporte privilegiado de ensino cívico.

Essa diminuição da parte efetiva atribuída à instrução cívica nos programas oficiais traduz-se nos números da produção editorial: somente 44 novas obras foram publicadas no periodo entre guerras, sendo que mais da metade entre 1921 e 1925.

Alguns meses depois da invasão da França pelas tropas alemãs, a portaria de 23 de novembro de 1940 apresenta a concepção do regime de Vichy sobre a instrução cívica: "Os professores deverão revalorizar os sentimentos e as idéias cujo desaparecimento ou mesmo o simples enfraquecimento nos espíritos e nos corações deve ser considerado como perigoso para o Estado e para a Pátria. Nessa mesma perspectiva, as noções de Instrução Cívica são simplificadas e reduzidas ao essencial". Em conseqüência disso, a instrução cívica desaparece dos programas de todas as classes da escola elementar em proveito de um ensino moral recentralizado sobre noções de trabalho, família e pátria. ${ }^{17}$ Ela é relegada ao segundo ano das escolas primárias superiores e organiza-se em torno de temas, tais como: "Papel e função do Estado. Condições indispensáveis ao seu funcionamento: ordem, autoridade, justiça. A hierarquia e as elites. Por que elas são necessárias a um Estado bem ordenado. Fidelidade ao Estado, ao seu Chefe, a suas leis, às autoridades". O fato de que somente um manual de instrução moral e cívica, o de E. Primaire, publicado pela primeira vez em 1902, figure nas listas sucessivas de manuais proibidos pelas autoridade de Vichy, listas que contêm em contrapartida várias dezenas de títulos de manuais de história, confirma o desinteresse de que essa disciplina é objeto ao final da Terceira República. Mas, levando-se em consideração a redução do mercado e das dificuldades com o fornecimento de papel, uma pequena dezena de novos manuais será composta durante a Ocupação.

\section{4 - De 1945 ao nossos dias: generalização do ensino cívico}

Após a Liberação, parece necessário reforçar a coesão nacional e renovar a democracia. Inspirada nas propostas do plano Langevin-Wallon conhecido em Argel no fim da guerra, a organização do ensino moral e cívico, adotado a partir de 1945 pelo inspetor geral Louis François, marca uma ruptura com os períodos precedentes. Até esse momento, somente os alunos que freqüentavam os estabelecimentos de ensino primário recebiam uma formação moral e civica no âmbito escolar; os alunos de categorias sociais mais elevadas que faziam sua trajetória escolar nos liceus recebiam tal formação de suas famílias. A instrução moral e cívica é introduzida no segundo grau, inicialmente no primeiro ciclo (alunos de 11 a 16 anos, em média), pelas portarias de 26 e 27 de 1945 e pela circular de 27 de junho

17 O tripé "Trabalho, familia, pátria" descarta a divisa republicana "Liberdade, igualdade, fraternidade". 
de 1945, depois no segundo ciclo (alunos de 16 a 19 anos, em média) pela portaria de 27 de março de 1948 e pela circular de 10 de maio de 1948. Paralelamente, as portarias de 17 de outubro de 1945, 24 de julho de 1947, depois de 23 de novembro de 1956, fundem os programas do primeiro grau. Pela primeira vez na França, é dispensado um ensino moral e cívico coerente e progressivo que se refira ao conjunto da população escolar. Considerando a limitação do papel, é preciso esperar até junho de 1948 para retomar a produção: a partir dessa data, é essencialmente em direção ao ensino secundário e, a partir dos anos sessenta, ao ensino técnico, que vai se situar a oferta editorial; o crescimento demográfico, a democratização do ensino e a prolongação da escolaridade obrigatória até dezesseis anos abrem então aos editores um mercado propício. Em quinze anos, de 1962 a 1976, mais de cem novos títulos são publicados. Uma suspensão repentina ocorre em 1976: a educação cívica é então integrada ao conjunto história-geografiainiciação econômica impedindo, por um tempo, a elaboração de manuais específicos. Em contrapartida, a volta da educação cívica enquanto disciplina autônoma, sob o ministério de Jean-Pierre Chevènement, em 1985, marca o retorno à tradição da Terceira República e suscita a composição de um número considerável de novas obras para utilização nos diversos niveis do ensino.

Porém, a educação cívica não conquistou apenas, nesses últimos cinqüenta anos, novos públicos escolares, cobrindo progressivamente o conjunto dos niveis e tipos de ensino. Ela integrou novos objetivos, conheceu - com um eclipse de uma dezena de anos, de 1975 a 1985 - uma intensificação nos seus conteúdos e uma extensão de suas áreas de aplicação, desde a iniciação ao primeiros-socorros (1958) ou o código de trânsito (1959) até os fundamentos de uma cidadania européia, a luta contra as discriminações ou a defesa do meio ambiente: "A formação do cidadão compreende uma educação para a civilidade, uma educação para a vida em sociedade, uma educação cívica no sentido político que designa a iniciação às formas da vida política, às instituições e ao seu funcionamento."18 Ela renovou seus métodos: os programas de 1985, retomando as abordagens anteriores, notadamente aquelas dos programas de 1882, articulavam-se em torno de uma progressão que ia das instituições locais às instituições nacionais e internacionais; aqueles de 1995 e 1997 organizam-se em torno de noções fundamentais - a pessoa humana e o cidadão - segundo uma progressão que supostamente leva em consideração a idade e o nivel do alunos: "Os valores e os princípios da democracia fundam-se sobre os direitos do homem. [...] Esses valores e principios correspondem aos conceitos chaves que, com os alunos, são apreendidos e construídos a partir de estudos de caso. O aprofundamento desses conceitos marca o itinerário cívico dos alunos." 19 Paralelamente, surgem iniciativas visando inscrever os princípios democráticos na vida cotidiana dos estabelecimentos (delegados de turma, conselhos municipais da criança, jornais de liceus, etc.).

18 Portaria de 10 de janeiro de 1997.

19

Ibid. 


\section{5 - Um balanço moderado}

Os debates que suscita o papel que a instituição escolar deve desempenhar na formação do cidadão estão hoje longe de estarem encerrados: a instrução civica supõe um consenso sobre um certo número de valores; a disparidade de opiniōes políticas, de crenças religiosas e de comportamentos sociais faz dela uma disciplina de risco e torna delicada a posição dos professores. Seguramente, esta é uma das explicações à variação que o historiador constata entre as intenções manifestas dos responsáveis pela instituição e a prática cotidiana das salas de aula.

A criação de um ensino de moral e cívica no início da Terceira República corresponde a um período de militantismo: trata-se, para os responsáveis do sistema educativo, mas também para a maioria dos professores, de despertar a adesão aos principios fundadores da democracia. Assim, em 1883, numerosos professores primários escolhem os manuais escolares de instrução civica em lugar do livro de leitura; inversamente, encontram-se manuais de leitura com a rubrica 'instrução moral e cívica'. ${ }^{20} \mathrm{O}$ discurso cívico (e moral) não se restringe apenas aos manuais da disciplina: ele irradia-se pelo conjunto da produção escolar, geralmente de maneira implícita. ${ }^{21}$ Os livros de leitura apresentam grande quantidade de relatos patrióticos; os enunciados dos manuais de aritmética colocam em cena situações propícias ao conhecimento das instituições e ao desenvolvimento das virtudes cívicas; os manuais de história vangloriam os grandes homens da Revolução; os ditados, os exemplos gramaticais, os temas de redação, a instrução dos exercícios integram o mesmo objetivo ao qual a iconografia, que alcança agora 0 conteúdo dos livros escolares, confere uma forte carga emocional. A colocação em cena de personagens infantis acarreta um processo de identificação do leitor com o herói, como em Le petit citoyen [O pequeno cidadão], de Jules Simon, ou Les enfants de Marcel [As crianças de Marcel], de Bruno, cujo subtítulo, Instruction morale et civique. Livre de lecture courante [Instrução moral e cívica. Livro de leitura corrente], revela a imbricação voluntária de dois corpus disciplinares.

Contudo, desde o final do século passado, o entusiasmo manifestado pela instrução cívica cede lugar a uma visão mais critica, e o tempo que the consagram os professores primários em seu ensino não cessa de diminuir, fato testemunhado, entre outros, pela produção escolar. A extensão da instrução cívica - substituída em 1964 pela educação cívica ${ }^{22}$ - ao programa das turmas de $2^{\circ}$ grau após a Segunda Guerra Mundial manifesta as preocupações da instituição face à ignorância da juventude francesa, mas ela não responde às expectativas, como mostram inúmetas sondagens efetuadas entre 1957 e $1974 .{ }^{23}$ O ensino cívico peca não somente pela exigüidade dos horários que lhe são atribuídos, mas também pelo

20 Conforme nota 13. Le petit français, de Charles Bigot (10 departamentos sobre 31 analisados), Le petit citoyen, de Jules Simon (5), L'instruction moral et civique pour les petits enfants, de Bruno (3), etc. Ao contrário, Les lectures pratiques, de Jost et Braeuning (3).

21 Aqui, convém assinalar o pape! essencial desempenhado pelos livros de prêmios e os livros de bibliotecas escolares, escolhidos em listas estabelecidas pelo ministério de Instrução Pública, na formaçăo moral e civica da juventude francesa.

22 BLOCH, M. A. Instruction ou éducation civique? Éducation à la fraternité, n. 11, janvier-février 1964, p. 1-3.

23 Consultar Jean Vial e Alain Mougniotte. D'hier à demain, l'éducation civique et sociale. Toulouse: Erès, 1992, p. 57-67. 
comportamento dos professores: confrontados com a crise de valores e das instituições, mas também com programas carregados, especialmente de história e de geografia no secundário, um número significativo deles não lhe consagra o tempo regulamentar, chegando a se abster de ensiná-la. De certa maneira, a absorção da educação cívica nas ciências sociais ou nas disciplinas de estimulação, no quadro da reforma Haby de 1975, consagra essa atitude do corpo docente.

A reforma Chevènement de 1985 marca, é verdade, uma ruptura. Mas pode-se dizer, a partir disso, que, desde então, a educação cívica ganhou em eficácia? Mesmo que tenha um sentido, pois a escola não é, longe disso, o único lugar onde se pode efetuar a formação do cidadão, a questão permanece delicada. Há mais de um século que a oferta editorial não é tão intensa desde um século, mas o mercado dos manuais de educação cívica estagna: os editores calcularam que no nível do colégio, onde o Estado se comprometeu desde 1977 a financiar a cada quatro anos a renovação dos manuais, seriam necessários, no ritmo anual, 85 anos para substituir as coleções de livros de educação cívica. A penúria pela qual passam numerosos estabelecimentos escolares mostra claramente que o manual não é mais o vetor privilegiado da formação do cidadão. Mas, conservando à educação cívica um status de disciplina autônoma, possuidora de um programa específico, os textos oficiais mais recentes insistem sobre sua dimensão interdisciplinar e sobre a necessidade de inter-relacionar a diversidade dos aportes: "A educação cívica é tarefa de todos" [Nos colégios, o diretor] favorece o envolvimento de toda equipe educativa com a educação civica. Sobre certos temas do programa, os projetos comuns podem ser aplicados, às vezes com o apoio de colaboradores externos." ${ }^{4}$ Assim, a educação civica, centrada no aluno, dá hoje sentido ao conjunto do projeto educativo.

\section{DEnsino primário (elementar e superior) \\ Ensino secundário e técnico}

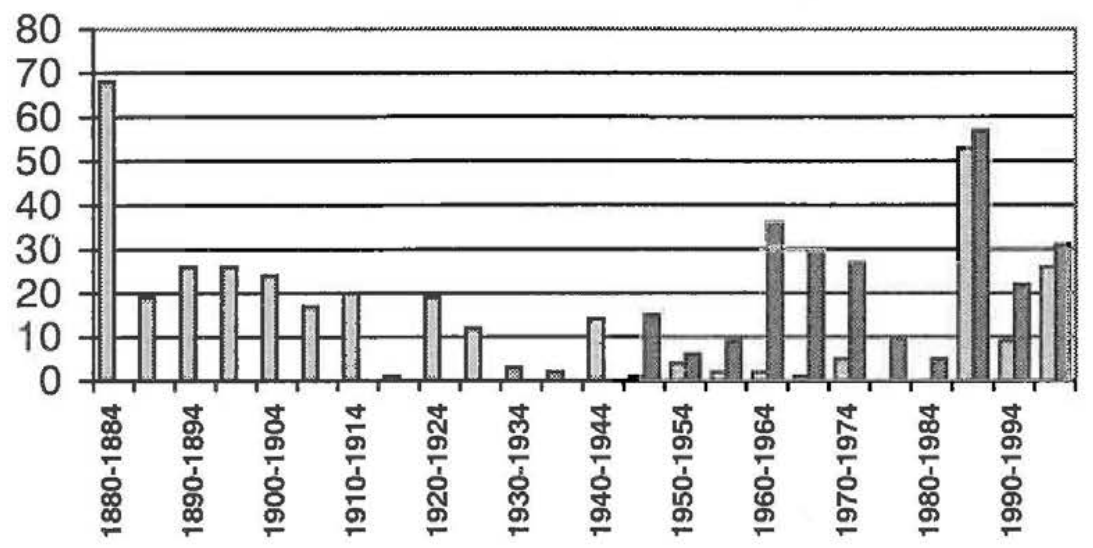

24 Portaria de 10 de janeiro 1997. 